\title{
Assessing the effectiveness of imperviousness on stormwater runoff in micro urban catchments by model simulation
}

\author{
Lei Yao, ${ }^{1,2}$ Liding Chen ${ }^{1}$ and Wei Wei ${ }^{1 *}$ \\ ${ }^{1}$ State Key Laboratory of Urban and Regional Ecology, Research Center for Eco-Environmental Sciences, Chinese Academy of Sciences, Shuangqing \\ Road 18, Haidian District, Beijing 100085, China \\ ${ }^{2}$ University of Chinese Academy of Sciences, Yuquan Road 19, Shijingshan District, Beijing 100049, China
}

\begin{abstract}
:
Imperviousness, considered as a critical indicator of the hydrologic impacts of urbanization, has gained increasing attention both in the research field and in practice. However, the effectiveness of imperviousness on rainfall-runoff dynamics has not been fully determined in a fine spatiotemporal scale. In this study, 69 drainage subareas $<1$ ha of a typical residential catchment in Beijing were selected to evaluate the hydrologic impacts of imperviousness, under a typical storm event with a 3-year return period. Two metrics, total impervious area (TIA) and effective impervious area (EIA), were identified to represent the impervious characteristics of the selected subareas. Three runoff variables, total runoff depth (TR), peak runoff depth (PR), and lag time (LT), were simulated by using a validated hydrologic model. Regression analyses were developed to explore the quantitative associations between imperviousness and runoff variables. Then, three scenarios were established to test the applicability of the results in considering the different infiltration conditions. Our results showed that runoff variables are significantly related to imperviousness. However, the hydrologic performances of TIA and EIA were scale dependent. Specifically, with finer spatial scale and the condition heavy rainfall, TIA rather than EIA was found to contribute more to TR and PR. EIA tended to have a greater impact on LT and showed a negative relationship. Moreover, the relative significance of TIA and EIA was maintained under the different infiltration conditions. These findings may provide potential implications for landscape and drainage design in urban areas, which help to mitigate the runoff risk. Copyright (C) 2015 John Wiley \& Sons, Ltd.
\end{abstract}

KEY WORDS impervious surfaces; rainfall-runoff; SWMM; scenario analysis; urban planning

Received 4 February 2015; Accepted 18 November 2015

\section{INTRODUCTION}

Urbanization has occurred over several decades, and is manifested as a drastic concentration of impervious surfaces such as diverse buildings, roads, and other paved areas. An increased proportion of impervious surfaces associated with the urbanization process can result in decreased rainfall infiltration and increased hydraulic efficiency and surface runoff (Dunne and Leopold, 1978; Shuster et al., 2005; Paul and Meyer, 2008). As the imperviousness increases, the runoff response is amplified significantly. For example, runoff can increase twofold (fivefold) when the impervious coverage increases to $10-20 \%(75-100 \%)$ over natural

\footnotetext{
*Correspondence to: Wei Wei, State Key Laboratory of Urban and Regional Ecology, Research Center for Eco-Environmental Sciences, Chinese Academy of Sciences, Shuangqing Road 18, Haidian District, Beijing 100085, China.

E-mail: weiwei@rcees.ac.cn

Contract/grant sponsor: Key Project of the National Natural Science Foundation of China; Innovation Project of the State Key Laboratory of Urban and Regional Ecology of China; contract/grant numbers: 41230633 ; SKLURE2013-1-02.
}

ground catchment (Arnold and Gibbons, 1996). In general, large volumes of surface runoff result in increased severity of flooding. Moreover, potential property damage from floods can be enormous with increased property values in urban areas. Managing stormwater runoff and preventing potential floods by regulating imperviousness are serious concerns in urban water management (Niemczynowicz, 1999; Schmitt et al., 2004; Jha et al., 2012); therefore, understanding the relationship between impervious coverage and its hydrologic impacts is critical.

Studies on the hydrologic impacts of urbanization generally tend to employ metrics easily accessed to characterize the features of imperviousness (Jacobson, 2011). The most important indicator of imperviousness is total impervious area (TIA), which is a lumped metric describing the entire fraction of impervious area. TIA can effectively reflect the development magnitude of a watershed, indicating the amount of rainfall directly converted to surface runoff (Finkenbine et al., 2000; Olivera and DeFee, 2007). However, it cannot represent the relative proximity of 
the isolated elements of impervious surfaces to the drainage network. Potential storage and the concentration of runoff with subsequent conveyance of pervious surfaces located in subsequent flow paths may significantly interfere with runoff response (Shuster et al., 2005). Thus, the effective impervious area (EIA) is defined as an impervious area directly connected to a drainage system, such as a street or buildings with gutters to efficiently drain runoff from the source area. Runoff from EIA drains directly into drainage systems; thus, EIA can produce sufficient surface runoff even under small rainfall events. Additionally, excess runoff may be intercepted and infiltrated from impervious surfaces that are not directly connected to drainage networks (Walsh et al., 2005).

Many studies discussing the hydrologic significances of TIA and EIA have determined that an overestimation always occurs in runoff response in urban catchments when using TIA as the predictor, whereas the EIA performance is better for the majority of hydrologic alternation because of urbanization (Shuster et al., 2005; Jacobson, 2011). However, most conclusions were drawn in large urban watersheds for the interest of fluvial floods (Alley and Veenhuis, 1983; Hatt et al., 2004; Yang et al., 2011). The contributions of TIA and EIA on rainfall-runoff have not been fully compared in fine-scaled urban catchments such as urban communities, neighbourhoods, land parcels, or even more detailed scales that undergo severe pluvial hazards because of improper landscape/drainage design (Qin et al., 2013). Limited drainage areas and shorter drainage lengths in small urban catchments in particular may prompt hydrologic processes (Dunne and Leopold, 1978). Moreover, previous studies focusing on fine-scale catchments have usually adopted long-term or continuous rainfall-runoff data (Lee and Heaney, 2003; Dietz and Clausen, 2008). These studies give general information on the hydrologic performances of imperviousness over a long-term scale. However, they may overlook the individualities caused by specific rainfall events, particularly flood-induced rainfall conditions, and thus weaken the realistic short-term predictive abilities for flood management (Tayfur and Singh, 2006; Talei and Chua, 2012). This occurs because runoff responses depend on the given rainfall events significantly in urban regions (Ramier et al., 2011). Similar findings obtained by Boyd et al. (1993) indicate that runoff contributions of different land surfaces within a catchment vary with rainfall and infiltration conditions. Such phenomena may lead to various performances of TIA and EIA on rainfall-runoff in studies based on different spatiotemporal scales and thus limit the potential applicability of previous findings. Therefore, understanding the role of TIA/EIA in predicting rainfallrunoff at finer scales may expand the current knowledge of the effectiveness of imperviousness on urban runoff.
Furthermore, micro urban catchments function as elementary drainage units for urban storm sewer systems. Landscape changes within these catchments result in varied rainfall-runoff responses and can alter the entire drainage process of a city (Meierdiercks et al., 2010). Therefore, knowledge of the effects of TIA/EIA on rainfall-runoff in micro urban catchments can also benefit urban drainage system design and landscape planning.

In this study, a scale- and storm-independent analysis was conducted in a high-density residential area in Beijing to understand how TIA and EIA affect rainfallrunoff responses in micro urban catchments under a similar flooding condition. According to the drainage features, the study area was delineated into several subareas as basic research units. Detailed land cover and imperviousness characteristics were identified through geographic information system (GIS) and field investigation. Runoff variables of each subarea were simulated by using a validated hydrologic model. The relative significance of TIA and EIA on different runoff variables was quantified. Additionally, variations in the performances of imperviousness with different infiltration conditions were examined on the basis of the three assumptive scenarios.

\section{MATERIALS AND METHODS}

\section{Study area}

The Wangchunyuan residential site (WCY), located in the northern part of central Beijing's built-up region $\left(40^{\circ} 2^{\prime}\right.$ $\mathrm{N}, 116^{\circ} 24^{\prime} \mathrm{E}$ ), was selected as the case-study area (Figure 1). As one of the largest and newest residential zones in Beijing, the WCY is built since 2008 and covers 11 ha, including high-rise buildings for dense residential needs. Four separate sewer networks are built to discharge the runoff generated from the WCY into the municipal drainage system via four stormwater outlets (Figure 1). Owing to the absence of systematic landscape design for stormwater prevention, however, severe waterlogging hazards have occurred more frequently in the WCY and other similar urban areas during recent years. Evaluating the relationship between imperviousness and the rainfall-runoff process in such small urban catchments may help urban planners to better understand specific urban design and stormwater regulation. Moreover, the typical architecture pattern of the WCY can be applied other residential catchments in Beijing.

\section{Spatial analysis}

Land cover information of the WCY was identified based on satellite image interpretation and field investigation (Figure 1). First, land covers in the WCY were visually outlined based on ortho-rectified satellite image. The image was captured by using Google Earth Pro 

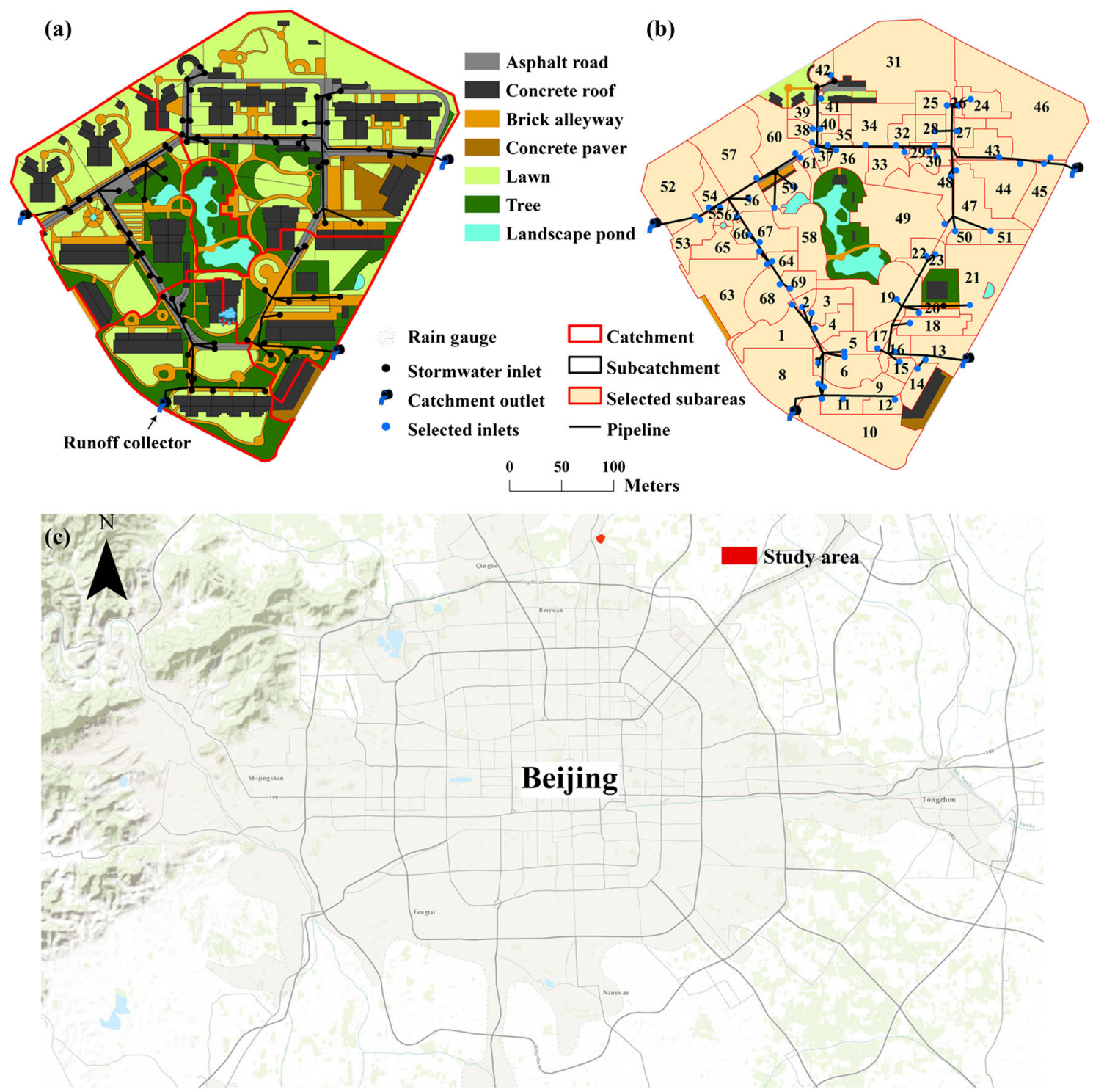

Figure 1. Spatial information of WCY. (a) Land cover, drainage layout, and monitor instruments in WCY, (b) subareas for analysis, (c) spatial location of WCY in Beijing

software, and its data source was QuickBird image with 0.61-m spatial resolution provided (DigitalGlobal Co.). The high spatial resolution of the applied satellite image meets the requirement of land cover and imperviousness identification (Roy and Shuster, 2009). An auxiliary ground-truthing process was also conducted in summer 2013 to confirm and validate the land cover data. In general, land cover types in the WCY consist of asphalt roads, concrete pavers, concrete roofs, brick alleyways, lawns, stand-alone trees with bare soil pits, and landscape ponds. Inlet nodes and conduits of the drainage system in the WCY were digitized into a GIS layer (Figure 1).

The TIA was estimated by land cover analysis based on the satellite image interpretation, which has been well documented (Jacobson, 2011). We conducted a detailed visual interpretation from the high-resolution images to obtain the TIA information by assigning land cover types. Asphalt roads, concrete pavers, concrete roofs, and brick alleyways were confirmed as impervious surfaces; therefore, their total area was treated as TIA.

EIA estimation requires determination of the impervious areas connected to sewer networks. However, several factors such as various urban building forms, complex drainage conditions, and insufficient data interfere with accurate estimation of EIA in urban catchments (Shuster et al., 2005; Yang et al., 2011). Some researchers adopted empirical equations to predict EIA from the perspective of typical urban morphology (Alley and Veenhuis, 1983; Wenger et al., 2008). Boyd, et al. (1993; 1994) used a statistical method to estimate the EIA fraction in small 
urban catchments based on monitored rainfall-runoff data. However, these approaches were limited by differences in urban morphology (Han and Burian, 2009) and ungauged conditions for data monitoring. Moreover, only the lumped amount of EIA can be obtained by using these methods. In this study, detailed spatial distribution characteristics of EIA are required for sub-catchments delineation. Therefore, with reference to the standard methods of Lee and Heaney (2003) and Roy and Shuster (2009), a field-aided investigation was conducted to estimate the EIA fraction based on the GIS layer. Figure 1 (b) shows that most of the stormwater inlets were distributed on the asphalt roads in the WCY. We thus assumed that all total asphalt roads were EIA because asphalt roads with gutters usually play important roles in transferring surface runoff and augment the drainage network (Rodriguez et al., 2008; Meierdiercks et al., 2010). Then, field assessment was conducted from the sidewalks and building sides to confirm the structures and connectivity of brick alleyways as well as the ground locations of building roof downspouts in the WCY. Brick alleyways with curbs and surfaces lower than the surrounding area can easily gather and transfer runoff and thus were treated as EIA. Roof surfaces were segmented into several patches according to their downspouts (Lee and Heaney, 2003). Those located on directly connected impervious surfaces were considered as EIA.

\section{Modelling preparation}

Complicated drainage conditions such as intricate microtopography, multi-layer urban canopies, and unclear catchment boundaries pose challenge for rainfall-runoff data acquisition and analysis in small urban catchments (Jia et al., 2001). Hydrologic models help to resolve the complexity of reality and provide a reasonable method for simulating rainfall-runoff processes. Therefore, the Storm Water Management Model (SWMM, version 5.0) was chosen as the modelling platform for this research. SWMM is widely used for single- or long-term event simulation of runoff quantity and quality in urban areas (Zoppou, 2001; Rossman, 2010). The spatially explicit character of SWMM allowed us to build high-resolution model to characterize the complicated overland flow routing and to examine the potential influence of TIA/EIA on rainfall-runoff.

The core process in SWMM delineates the targeted catchment into a collection of sub-catchments that receive rainfall and generate runoff, then transport excess stormwater from sub-catchments to assigned outlets through sewer networks (Rossman, 2010). As shown in Figure 1, the WCY was first divided into four catchments assigned to outlets. Following the high-resolution discretization procedure of Krebs et al. (2014), further catchment delineations were made based on the underly- ing characteristics of land cover and imperviousness as well as the drainage network data. Each catchment surface was initially subdivided along with the boundary of unique land cover type. The linear street network including asphalt roads and brick alleyways that function as artificial corridors to regulate runoff transportation, were also adopted as sub-catchment boundaries (Jones et al., 2000; Zhang et al., 2012). Finally, the boundaries of TIA and EIA patches obtained by the above identification were used for further delineation. As a result, 441 sub-catchments were obtained, each of which was assigned homogenous spatial and hydrologic properties. Delineation of subcatchments in SWMM provided a spatially distributed approach for urban hydrology modelling, and the spatial relationship among sub-catchments was characterized by overland flow routing (Krebs et al., 2014). General runoff routing described in the SWMM model was generated from upstream disconnected impervious sub-catchments and flowed through down-stream pervious sub-catchments. It was then transferred to the EIA sub-catchments and finally drained to the stormwater inlet of the drainage network. Accordingly, a total of 73 subareas were lumped as basic study units with the sub-catchments assigned with the same stormwater inlets.

In SWMM, each sub-catchment is treated as a nonlinear reservoir. Total runoff, runon, and infiltration loss of each sub-catchment can be simulated separately in this model. Runoff contribution of single sub-catchment is calculated as part of the total runoff excluding runon, which is closely related to its hydrological characteristics, such as flow path, roughness, surface depression, evaporation, and ground infiltration (Skotnickia and Sowińskia, 2013). Depression capacities for underlying surfaces can be directly characterized in SWMM. Many continuous observations reported that evaporation as well as infiltration through impervious areas results in considerable reductions in urban runoff (Ragab et al., 2003; Berthier, et al., 2004; Ramier et al. 2011). The potential contribution of soil to sewer flow through parasitic infiltration process has also been reported (Rodriguez et al., 2008). In the present study, however, event-based simulation with short storm duration may not have provided sufficient time for these processes (Ragab et al., 2003). Thus, we did not include such runoff loss processes during the modelling. For infiltration losses, only those from pervious surfaces were considered. The Horton equation was adopted to calculate infiltration because it can effectively explain the two parts of total infiltration reduction within a runoff event: reduction because of initial soil wetting and infiltration at a constant rate throughout the runoff event (Guo and Adams, 1998). Kinematic wave theory was used for runoff routing computation. Several dominant parameters for conceptualizing the sub-catchments were derived first from spatial 
data sources such as drainage area and flow width in addition to drainage mapping including stormwater inlets and conduit parameters. The remaining model-control parameters were adjusted to fit the prediction results with the monitored results through model calibration.

Hydrologic data for model calibration were collected during the rainy season in 2013. A tipping-bucket rain gauge, with 5-min recording steps during the field trails was placed on a building roof. Moreover, an automatic flow collector was installed at the stormwater outlet of the WCY to record runoff at the same intervals (Figure 1). Three effective rainfall-runoff samples were collected on 15 July and 11 August, both for validation, and 4 September for calibration. The southern catchment with monitoring instruments was selected for model calibration, as shown in Figure 1. Because the same paving materials were used, the calibrated parameter in this catchment can be applied to other catchments. Rainfallrunoff data of the three events were used for model calibration and validation by using the genetic optimization algorithm (James, 2003). Model performance evaluation was assessed with linear correlation coefficient $(r)$ and Nash-Sutcliffe efficiency (NSE) (Nash and Sutcliffe, 1970). As shown in Figure 2, the calibrated model accurately presented the actual conditions and described rainfall-runoff process well. The calibrated infiltration parameters of pervious surfaces including initial infiltration rate $(\mathrm{mm} / \mathrm{h})$, saturated infiltration rate $(\mathrm{mm} / \mathrm{h})$, and decay factor $(1 / \mathrm{h})$ were $103.81,11.44$, and 8.46 , respectively; the other parameters are listed in Table I.

\section{Designed storm and infiltration scenarios}

To better represent the actual urban flooding conditions, the simulation experiment was conducted under a typical flood-driven storm event. To meet the requirements of flood discharge, the standard of the storm return period for the drainage system design was between one and three years in suburban areas of Chinese cities (GB50014-2006, 2013). The potential flooding risk will increase if the rainfall amount exceeds this standard because the drainage system may not be able to accommodate the excess stormwater in the urbanized catchments such as those at residential or commercial sites. Therefore, the drainage design standard in such catchments can represent their potential flood control requirement. We thus chose the maximum standard of rainfall event with a three-year return period to explore the relationship between imperviousness and rainfall-runoff.

The storm event was cast according to the rainfall intensity formula in Beijing (Wang et al., 2011; GB50014-2006, 2013), as shown in the following equation. The rainfall hyetograph was generated by using Chicago storm profile, usually adopted for urban drainage design in urban catchments (Qin et al., 2013).

$$
i=12.004 \times(1+0.81 \times \log P) /(t+8)^{0.711}
$$

where $i$ is rainfall intensity $(\mathrm{mm} / \mathrm{min}), t$ is rainfall duration (min), and $P$ is the return period (three years). Beijing's typical rainfall characteristics were used including 120-min rainfall duration and 0.3 peak rainfall coefficient, which is the ratio of peak time to total duration (Wang et al., 2011).

Additionally, the infiltration conditions of pervious areas are important factors in rainfall-runoff responses in urban catchments (Boyd et al., 1994; Guo and Adams, 1998). Thus, three levels of infiltration scenarios were established to examine whether our results were applicable for extrapolation to other urban watersheds with different types of pervious surfaces. The infiltration
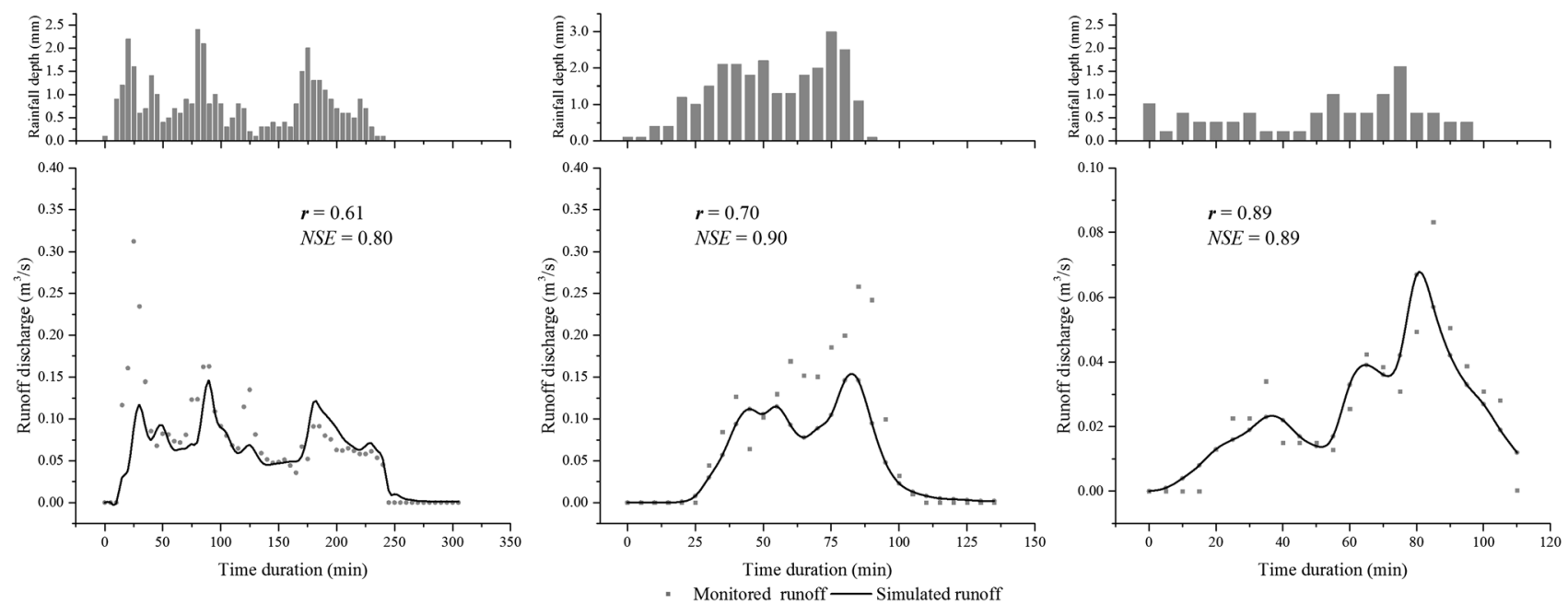

Figure 2. Comparison of monitored and simulated runoff data, (a) 15 July 2013, (b) 11 August 2013, (3) 4 September 2013. $r$ : linear correlation coefficient, NSE: Nash-Sutcliffe efficiency 
Table I. Calibrated parameters for SWMM modelling

Manning's roughness Depression storage (mm)

Land cover

Asphalt road $\quad 0.017$

Concrete paver 0.008

0.675

Concrete roof 0.008

Brick alleyway 0.011

Lawn $\quad 0.266$

Tree $\quad 0.15$

Conduit

Concrete

0.0123

conditions, calibrated by using SWMM, were simply designed as moderate, low, and high infiltration with capacities of the current infiltration, half of the current infiltration, and double the current infiltration, respectively.

Details of the design scenarios are listed in Table II; each scenario corresponds to one time run in SWMM.

\section{Data analysis}

Leopold (1968) noted that changes in total runoff and peak flow characteristics were the most significant indicators for representing the relationship between surface runoff and urbanization. In this study, three critical hydrologic parameters were chosen as dependent variables to describe rainfall-runoff processes: total runoff depth (TR, mm), peak runoff depth (PR, $\mathrm{mm} / \mathrm{min}$ ), and lag time (LT, h, representing the timespan for peak runoff; Leopold, 1968; Paul and Meyer, 2008). TIA/EIA and land cover proportions were chosen as explanatory variables for exploring the relationship between imperviousness and rainfall-runoff.

To avoid the hydraulic influences of drainage systems (Meierdiercks et al., 2010; Ogden et al., 2011), we chose the subareas assigned with unique stormwater inlets as research units (Figure 1). We ruled out four subareas to avoid hydraulic distraction by sewer pipelines where their inlets receive additional runoff from upstream subareas. Therefore, 69 subareas were selected for study. The selected inlets are marked in blue in Figure 1, and the assigned subareas were recorded with unique numbers. Subarea runoff data under each scenario were derived

Table II. Storm and infiltration conditions of designed scenarios

\begin{tabular}{lll}
\hline & $\begin{array}{c}\text { Input rainfall } \\
\text { (rainfall amount) }\end{array}$ & $\begin{array}{c}\text { Infiltration conditions } \\
\text { of pervious surfaces } \\
\text { (steady infiltration rate) }\end{array}$ \\
\hline Scenario 1 & 3-year $(64.8 \mathrm{~mm})$ & Moderate-infiltration $(11.44 \mathrm{~mm} / \mathrm{h})$ \\
Scenario 2 & 3-year $(64.8 \mathrm{~mm})$ & Low-infiltration $(5.72 \mathrm{~mm} / \mathrm{h})$ \\
Scenario 3 & 3-year $(64.8 \mathrm{~mm})$ & High-infiltration $(22.88 \mathrm{~mm} / \mathrm{h})$ \\
\hline
\end{tabular}

Copyright () 2015 John Wiley \& Sons, Ltd. directly from the model output file assigned to each inlet node. Moreover, spatial information of TIA/EIA as well as land cover within each subarea was summarized on the basis of the spatial analysis.

Basic descriptive statistics were used to describe the spatial information and runoff data of the 69 subareas. Stepwise regression analysis was developed to explore the relationships between imperviousness and runoff characteristics. This analysis method can represent a simple model sufficient for capturing the significant fraction of impact factors and is widely used to select descriptive variables for relating hydrologic metrics to landscape descriptors (Ssegane et al., 2012; Shen et al., 2014). In this study, two groups of stepwise multiple regression analysis were performed under each scenario to determine the direction and magnitude of the interaction between spatial data and the individual runoff variables. Group 1 described the runoff characteristics as a function of land cover composition. Group 2 added proportions of TIA and EIA to examine their prediction values for rainfall-runoff, and their relative predictive importance. These regression models contain one or more independent variables linear equation coefficient, these coefficients can be the best predictor of the runoff variables. In these models, the unstandardized regression coefficients represent the linear coefficients of explanatory variables, while the standardized coefficients are used to determine the relative importance of explanatory variables by eliminating the influence of variable dimension: the larger absolute value of standardized coefficient, the more important a variable. Prior to analysis, all the regression models passed the tests of collinearity for TIA and EIA and residual analysis such as normality, homoscedasticity and independence test. Enter and remove thresholds for independent variable selection were at 0.05 and 0.1 , respectively. If the F-probability of an independent variable is less than the enter level, it will be chosen into the regression model; if the F-probability is greater than the remove level, it will be removed from the model.

\section{RESULTS}

\section{Land cover and imperviousness characteristics}

For the 69 subareas, the average area was 0.15 ha, and the total area was 10.43 ha. The largest subarea reached 0.77 ha, and the minimum area was 0.02 ha. Lawn was the dominant land cover type with a total area of 3.60 ha, followed by concrete roofs at 2.16 ha, brick alleyways at 2.00 ha, trees at $1.54 \mathrm{ha}$, and asphalt roads at $0.87 \mathrm{ha}$. Concrete pavers had the smallest fraction, $0.25 \mathrm{ha}$, which was used as the residential site square.

Details of land cover composition within each subarea are shown in Figure 3. The total area of TIA and EIA in the WCY reached 5.28 ha and 3.37 ha, respectively. Roof 


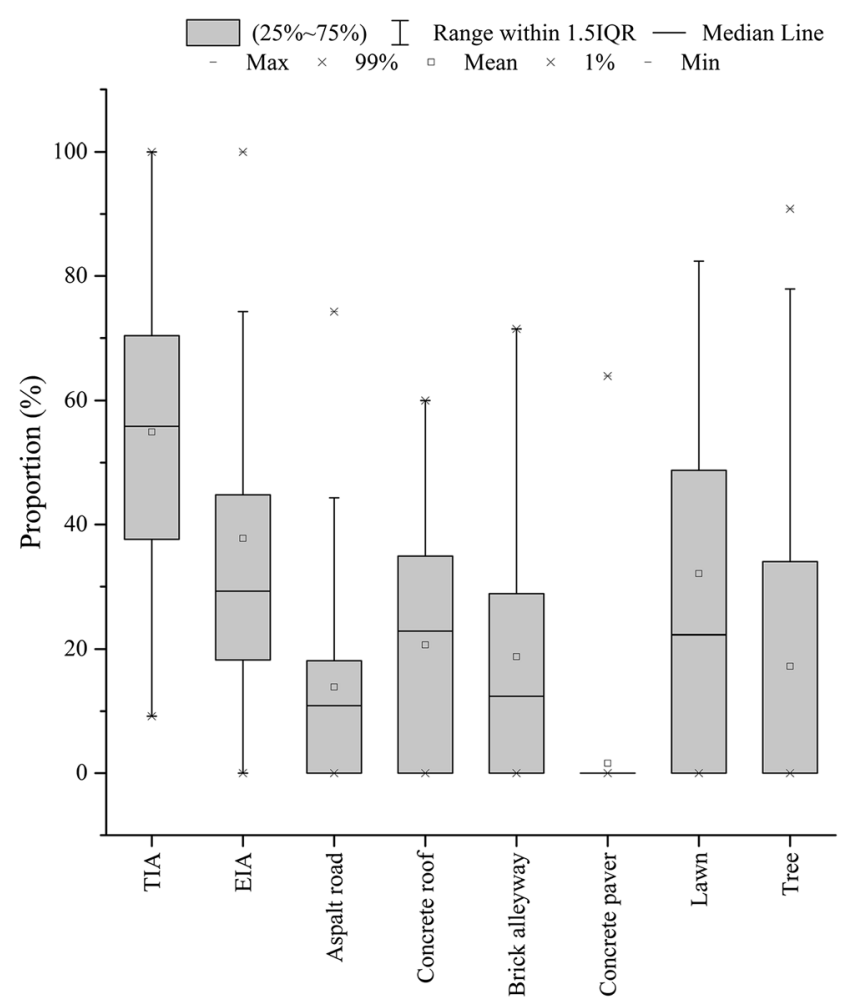

Figure 3. Imperviousness and land cover proportions within subareas

surfaces contributed the most TIA, followed by brick alleyways, asphalt roads, and concrete pavers. The EIA was mainly contributed by roads, including all asphalt roads and most of brick alleyways. Brick alleyways acted as the dominate land cover of EIA, followed by asphalt roads, concrete roofs, and concrete pavers. The TIA and EIA varied widely across the subareas (Figure 3 ). The mean TIA was 0.08 ha, ranging from $59.17 \mathrm{~m}^{2}$ to 0.36 ha. The average EIA, 0.05 ha, was lower than that of TIA, whereas three subareas 25, 28, and 59, had no EIA; the largest EIA reached $0.22 \mathrm{ha}$. Additionally, the mean percentage of TIA was $54.93 \%$, ranging from $9.17 \%$ to $100 \%$; the percentage of EIA ranged from zero to $100 \%$ with an average value of $37.77 \%$. Within 41 out of all subareas, the proportions of TIA were higher than that of EIA, and impervious surfaces in the remaining subareas were entirely connected with drainage system.

\section{Runoff characteristics}

Similar to imperviousness, the simulated runoff characteristics of each subarea varied greatly (Table III). The designated infiltration scenarios significantly altered the TR of the selected subareas, whereas they had only a slight influence on the PR and LT. Specifically, with the same maximum values, the average TR of the selected subareas decreased significantly at the 0.05 level from $51.73 \mathrm{~mm}$ to $41.04 \mathrm{~mm}$ as the infiltration capacities

Table III. Runoff characteristics of subareas under three scenarios

\begin{tabular}{llllll}
\hline Scenario & Runoff variable & Min & Max & Mean & Standard deviation \\
\hline Scenario 1 & TR (mm) & 30.02 & 64.64 & 47.47 & 8.35 \\
& PR (mm/min) & 0.48 & 3.15 & 1.52 & 0.64 \\
Scenario 2 & LT (h) & 0.63 & 1.07 & 0.71 & 0.07 \\
& TR (mm) & 38.50 & 64.64 & 51.73 & 6.45 \\
Scenario 3 & PR (mm/min) & 0.57 & 3.15 & 1.57 & 0.63 \\
& LT (h) & 0.63 & 1.07 & 0.71 & 0.07 \\
& TR (mm) & 17.17 & 64.64 & 41.04 & 11.12 \\
& PR (mm/min) & 0.37 & 3.15 & 0.43 & 0.67 \\
\end{tabular}


increased. Moreover, the internal difference of TR within these subareas increased significantly. The average values of PR and LT, by contrast, varied slightly (not statistically significant, at the 0.05 level) among the different scenarios. Table III also indicates that the designated scenarios altered the least values of TR and PR as well as the maximum value of LT.

Runoff contribution of each type of sub-catchment is shown in Figure 4, indicating that different infiltration conditions had certain influences on the runoff contributions of different types of surfaces, particularly for pervious surfaces. However, for all three scenarios, impervious surfaces contributed more runoff than pervious surfaces. For scenario 1, with different surface depressions, impervious surfaces such as asphalt roads, concrete roofs, brick alleyways, and concrete pavers contributed runoff ranging from $58.06 \mathrm{~mm}$ to $64.77 \mathrm{~mm}$, with an average value of $64.27 \mathrm{~mm}$. Pervious areas also generated overland runoff, with the highest value of $33.05 \mathrm{~mm}$. For scenario 2, average runoff from impervious surfaces decreased to $64.07 \mathrm{~mm}$; that from pervious areas increased to $37.45 \mathrm{~mm}$. Compared with scenario 1 , the runoff contribution from impervious surfaces decreased slightly, but not statistically significant. Pervious surfaces showed significant change, with narrowed ranges from $19.97 \mathrm{~mm}$ to $41.38 \mathrm{~mm}$. In contrast, the change trends of scenario 3 were at opposite poles, where the average runoff of impervious surfaces was increased to $64.37 \mathrm{~mm}$. That from pervious areas decreased significantly to $13.26 \mathrm{~mm}$, with a range of $0-22.32 \mathrm{~mm}$.

\section{Effects of impervious surfaces on runoff}

The results of stepwise regression analysis were all significant at the 0.01 level and showed strong relation- ships between spatial characteristics and rainfall-runoff processes (Tables IV, V, and VI). Standard coefficients of primary dependent variables changed slightly, and their relative significance remained stable among the three scenarios. The detailed regression results are described as follows.

In group 1, TR, PR, and LT were all effectively explained by the land cover variables. For TR and PR, most of their variations could be explained by all of the impervious types. Among the types of land cover, brick alleyways acted as the most important variable in affecting both TR and PR, followed by asphalt roads and concrete roofs. All of the standardized coefficients of the included land cover variables were positive, which indicates that TR and PR increased with these variables. For LT, brick alleyways were also primary influencing factor. However, fewer types of land cover contributed to LT. For example, only brick alleyways and asphalt roads maintained their significances in predicting LT under scenario 1. Moreover, the negative coefficients of each variable suggested that increasing size of these land cover types would shorten the runoff LT.

In group 2, after introducing TIA and EIA into the regression analysis, the significances of all dependent variables changed. More than $96 \%$ of the variations in TR could be explained for all the scenarios. However, most of the land cover variables lost significance. TIA performed as the most dominant in predicting TR, whereas EIA contributed little or even lost significance. As the infiltration capacity of the pervious surfaces increased, a slight decrease in the contribution of TR was found; that of EIA increased correspondingly. In predicting PR, a combination of TIA, EIA, trees, and concrete pavers could explain more than $80 \%$ of the variations in PR. TIA also functioned as the most

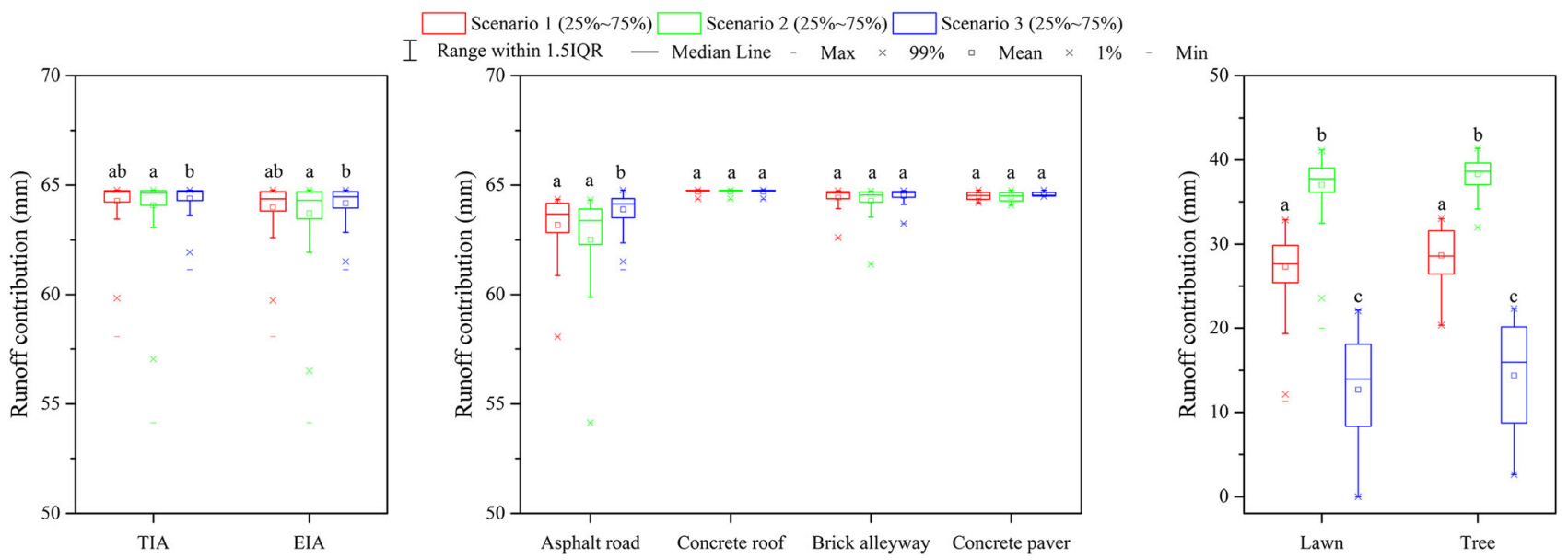

Figure 4. Runoff contributions of different types of sub-catchment under three scenarios. Different letters indicate significant differences in different infiltration conditions (at the 0.05 level) 
Table IV. Summary results for two groups of stepwise multiple regression analysis under scenario 1

\begin{tabular}{|c|c|c|c|c|c|c|c|c|c|c|}
\hline \multirow{2}{*}{$\begin{array}{l}\text { Dependent } \\
\text { variables }\end{array}$} & \multicolumn{9}{|c|}{ Explanatory variables with unstandardized regression coefficients/(standardized coefficients) } & \multirow[t]{2}{*}{$R^{2}$} \\
\hline & Ptia & Peia & Par & Pcr & $\mathrm{Pba}$ & Pcp & $\mathrm{Pla}$ & Ptr & Constant & \\
\hline \multicolumn{11}{|l|}{ Group 1} \\
\hline TR & - & - & $\begin{array}{l}40.266^{* *} \\
(0.774)\end{array}$ & $\begin{array}{l}36.035 * * \\
(0.775)\end{array}$ & $\begin{array}{c}39.387 * * \\
(0.951)\end{array}$ & $\begin{array}{l}39.250 * * \\
(0.402)\end{array}$ & & $\begin{array}{c}2.181 * * \\
(0.060)\end{array}$ & $26.035^{* *}$ & 0.968 \\
\hline PR & - & - & $\begin{array}{l}3.158 * * \\
(0.795)\end{array}$ & $\begin{array}{l}2.389 * * \\
(0.673)\end{array}$ & $\begin{array}{c}3.069 * * \\
(0.970)\end{array}$ & $\begin{array}{l}2.198 * * \\
(0.295)\end{array}$ & & $\begin{array}{c}0.510 * * \\
(0.184)\end{array}$ & -0.116 & 0.830 \\
\hline LT & - & - & $\begin{array}{l}-0.223 * * \\
(-0.527)\end{array}$ & & $\begin{array}{l}-0.182 * * \\
(-0.543)\end{array}$ & & & & $0.771 * *$ & 0.342 \\
\hline \multicolumn{11}{|l|}{ Group 2} \\
\hline TR & $\begin{array}{l}35.292 * * \\
(0.927)\end{array}$ & $\begin{array}{l}3.306 * * \\
(0.104)\end{array}$ & & & & & & $\begin{array}{c}2.256 * * \\
(0.062)\end{array}$ & $26.449 * *$ & 0.968 \\
\hline PR & $\begin{array}{l}2.131^{* *} \\
(0.733)\end{array}$ & $\begin{array}{l}0.782 * * \\
(0.322)\end{array}$ & & & & $\begin{array}{c}-0.858^{*} \\
(-0.115)\end{array}$ & & $\begin{array}{c}0.525 * * \\
(0.190)\end{array}$ & -0.027 & 0.847 \\
\hline LT & & $\begin{array}{l}-0.151 * * \\
(-0.587)\end{array}$ & & & & & & & $0.763 * *$ & 0.345 \\
\hline
\end{tabular}

Note: Explanatory variables for the models were abbreviated, where TR represents total runoff depth; PR, peak runoff depth; LT, lag time; Ptia, percent TIA; Peia, percent EIA; Par, percent asphalt road; Pcr, percent concrete roof; Pba, percent brick alleyway; Pcp, percent concrete paver; Pla, percent lawn; Ptr, percent tree.

*Coefficient is significant at the 0.05 level.

$* *$ Coefficient is significant at the 0.01 level.

important factor affecting PR, followed by EIA. After adding imperviousness to the regression analysis with LT, all dependent variables except EIA lost significance. EIA solely explained more than $30 \%$ of the variations in LT. Additionally, the negative coefficient of EIA implies that LT would decrease with an increase in EIA.

\section{DISCUSSIONS}

Hydrologic performance of imperviousness in micro urban catchment

The results indicated that even with similar regression $R^{2}$, imperviousness acted as a more effective and concise

Table V. Summary results for two groups of stepwise multiple regression analysis under scenario 2

\begin{tabular}{|c|c|c|c|c|c|c|c|c|c|c|}
\hline \multirow{2}{*}{$\begin{array}{l}\text { Dependent } \\
\text { variables }\end{array}$} & \multicolumn{9}{|c|}{ Explanatory variables with unstandardized regression coefficients/(standardized coefficients) } & \multirow[t]{2}{*}{$R^{2}$} \\
\hline & Ptia & Peia & Par & Pcr & $\mathrm{Pba}$ & Pcp & Pla & Ptr & Constant & \\
\hline \multicolumn{11}{|l|}{ Group 1} \\
\hline TR & - & - & $\begin{array}{l}31.218 * * \\
(0.776)\end{array}$ & $\begin{array}{l}28.269 * * \\
(0.787)\end{array}$ & $\begin{array}{l}30.725^{* * *} \\
(0.960)\end{array}$ & $\begin{array}{l}29.934 * * \\
(0.397)\end{array}$ & & $\begin{array}{l}2.668 * * \\
(0.095)\end{array}$ & $34.844 * *$ & 0.963 \\
\hline PR & - & - & $\begin{array}{l}3.054 * * \\
(0.782)\end{array}$ & $\begin{array}{l}2.315^{* *} \\
(0.664)\end{array}$ & $\begin{array}{l}3.075^{* *} \\
(0.989)\end{array}$ & $\begin{array}{l}2.117 * * \\
(0.289)\end{array}$ & & $\begin{array}{l}0.598^{* *} \\
(0.220)\end{array}$ & -0.048 & 0.827 \\
\hline LT & - & - & $\begin{array}{l}-0.255^{* *} \\
(-0.598)\end{array}$ & $\begin{array}{c}-0.085^{*} \\
(-0.224)\end{array}$ & $\begin{array}{l}-0.214 * * \\
(-0.632)\end{array}$ & & & & $0.171 * *$ & 0.392 \\
\hline \multicolumn{11}{|l|}{ Group 2} \\
\hline TR & $\begin{array}{l}30.760 * * \\
(1.045)\end{array}$ & & & $\begin{array}{c}-2.558 * \\
(-0.071)\end{array}$ & & & & $\begin{array}{l}2.680 * * \\
(0.096)\end{array}$ & $34.900 * *$ & 0.963 \\
\hline PR & $\begin{array}{l}2.065^{* *} \\
(0.723)\end{array}$ & $\begin{array}{c}0.810 * * \\
(0.340)\end{array}$ & & & & $\begin{array}{c}-0.909 * \\
(-0.124)\end{array}$ & & $\begin{array}{l}0.617 * * \\
(0.227)\end{array}$ & 0.037 & 0.845 \\
\hline LT & & $\begin{array}{l}-0.155^{* *} \\
(-0.595)\end{array}$ & & & & & & & $0.767 * *$ & 0.354 \\
\hline
\end{tabular}

*Coefficient is significant at the 0.05 level.

**Coefficient is significant at the 0.01 level. 
Table VI. Summary results for two groups of stepwise multiple regression analysis under scenario 3

\begin{tabular}{|c|c|c|c|c|c|c|c|c|c|c|}
\hline \multirow{2}{*}{$\begin{array}{l}\text { Dependent } \\
\text { variables }\end{array}$} & \multicolumn{9}{|c|}{ Explanatory variables with unstandardized regression coefficients/(standardized coefficients) } & \multirow[t]{2}{*}{$R^{2}$} \\
\hline & Ptia & Peia & Par & Pcr & $\mathrm{Pba}$ & Pcp & Pla & Ptr & Constant & \\
\hline \multicolumn{11}{|l|}{ Group 1} \\
\hline TR & - & - & $\begin{array}{l}53.986 * * \\
(0.779)\end{array}$ & $\begin{array}{l}44.215 * * \\
(0.714)\end{array}$ & $\begin{array}{l}52.597 * * \\
(0.953)\end{array}$ & $\begin{array}{l}52.603 * * \\
(0.405)\end{array}$ & & & $13.689 * *$ & 0.966 \\
\hline PR & - & - & $\begin{array}{l}3.351 * * \\
(0.808)\end{array}$ & $\begin{array}{l}3.396^{* *} \\
(0.646)\end{array}$ & $\begin{array}{l}3.238 * * \\
(0.980)\end{array}$ & $\begin{array}{c}2.356^{* *} \\
(0.303)\end{array}$ & & $\begin{array}{l}0.443 * * \\
(0.153)\end{array}$ & $-0.249 *$ & 0.844 \\
\hline $\mathrm{LT}$ & - & - & $\begin{array}{l}-0.167 * * \\
(-0.547)\end{array}$ & & $\begin{array}{l}-0.158 * * \\
(-0.651)\end{array}$ & $\begin{array}{l}-0.119 * \\
(-0.208)\end{array}$ & & & $0.750 * *$ & 0.439 \\
\hline \multicolumn{11}{|l|}{ Group 2} \\
\hline TR & $\begin{array}{l}42.040 * * \\
(0.828)\end{array}$ & $\begin{array}{l}8.465 * * \\
(0.200)\end{array}$ & & & & & & & $14.751 * *$ & 0.969 \\
\hline PR & $\begin{array}{l}2.103 * * \\
(0.692)\end{array}$ & $\begin{array}{c}0.937 * * \\
(0.370)\end{array}$ & & & & $\begin{array}{c}-0.859^{*} \\
(-0.110)\end{array}$ & & $\begin{array}{l}0.462 * * \\
(0.160)\end{array}$ & -0.142 & 0.864 \\
\hline $\mathrm{LT}$ & & $\begin{array}{l}-0.123 * * \\
(-0.664)\end{array}$ & & & & & & & $0.742 * *$ & 0.441 \\
\hline
\end{tabular}

*Coefficient is significant at the 0.05 level.

**Coefficient is significant at the 0.01 level.

factor in predicting runoff variables than land cover composition. Moreover, the two impervious metrics, TIA and EIA, had different strengths in determining the different runoff variables.

In this study, TIA performed as a more powerful factor in affecting the runoff depth (TR and PR) than EIA. Particularly for TR, the regression results showed that the standard coefficient of TIA was far above that of EIA. As shown in Figure 4, all of the impervious surfaces contributed substantial runoff. This contradicts previous findings such that EIA is a more dominant factor for runoff contribution in urban watersheds (Shuster et al., 2005; Jacobson, 2011). This contradiction may be caused by two major factors. The first is the micro spatial scale that we used in this study. Our study was conducted at a finer scale $(<1 \mathrm{ha})$, in which the hydrologic processes differ from those in previous studies conducted at coarse scales. The runoff timing response can be hours or even days in large urban watersheds $>100 \mathrm{~km}^{2}$ (Mejía and Moglen, 2009; Yang et al., 2011), whereas that in small catchments of $<10$ ha tends to respond more sensitively at $<1$ h. (Berthier et al., 2004; Hood et al., 2007). As shown in Table III, the runoff LTs of the subareas were also less than $1 \mathrm{~h}$. Additionally, the underground drainage network within these urbanized catchments facilitates the transmission of runoff. Micro scale urban catchments with shorter transfer time thus will limit the volume of runoff that can infiltrate into the soil, by affecting the time for which surface runoff remains on the land surface (Singh, 1997). Zhang and Shuster (2014) also found that runoff depth of micro catchments $(<1 \mathrm{ha})$ exhibited clear dependence on the mean flow distance of the catchments. This leads to a more prominent runoff contribution of disconnected impervious surfaces and shorter concentration time than that in larger areas (Rodriguez et al., 2008). Second, the average rainfall amounts adopted in previous studies based on continuous data are relatively low. For example, Lee and Heaney (2003) applied a long-term rainfall data with a total amount of $77809 \mathrm{~mm}$. However, the average rainfall depth per event in their study was less than $11 \mathrm{~mm}$, which might overlook the urban flooding condition. Therefore, we adopted a single rainfall event with a three-year return period as storm input to emphasize the flood-induced background. Different drainage patches in a watershed may present various runoff responses with different rainfall conditions (Boyd et al., 1993). Pervious surfaces such as lawns and tree lands may reach their saturated states rapidly under this rainfall condition and then function as runoff source areas rather than sink areas (Figure 4). After pervious surfaces reach their saturation conditions, runoff from disconnected impervious areas would be transferred to the stormwater inlets unrestrained. Therefore, under these conditions, TIA functioned as the primary factor affecting TR. A faster conflux as well as higher runoff discharge of impervious surfaces in micro urban catchments caused the PR to increase with TIA (Ogden et al., 2011).

However, TIA lost significance in affecting LT, whereas adding the proportion of EIA had more significant contribution on shortening the runoff LT in this study. As areas connected directly to drainage systems, stormwater inlets respond preferentially to runoff generated from EIA. Increasing EIA tends to 
shorten the concentration duration of runoff (Paul and Meyer, 2008). Faster concentration time is equivalent to decreasing the overall flow length of subareas which has been found to strongly correlate to LT with a positive coefficient of 0.97 (Watt and Chow, 1985). This explains why EIA acts as a more reasonable factor than TIA in predicting LT changes. Moreover, the changing rate of LT exhibited trends of slowing as EIA increased because the inherent runoff concentration duration of impervious surfaces suppressed the reducing momentum of LT.

\section{Applicability and implications}

Scenario analyses showed that changing infiltration conditions exerted certain influences on the runoff responses of the selected subareas, although the hydrologic significances of TIA and EIA were not altered. The primary predictor for each runoff variable remained stable mainly because the runoff gaps between impervious and pervious surfaces still exhibit high disparities with different infiltration scenarios (Figure 4). The robust performances of imperviousness suggest that our results can be applied to other sites with different infiltration conditions. Moreover, the designated 3-year return period is a typical flood-induced rainfall condition that relates to the drainage design criterion for flood control within the small catchments in the urban built-up regions (GB50014-2006, 2013). The assignment of this typical storm event to the 69 urbanized subareas involving wide ranges of TIA and EIA proportions in this study can provide a sufficient consideration of various drainage conditions and thus can enhance the regression results.

Our findings showed that the hydrologic effectiveness of imperviousness was scale dependent, which may complement the current studies and improve the insights on the hydrological effects of imperviousness in micro urban catchments assigned with a flood-induced background. Moreover, there is increasing interest in linking the emerging theory of urban ecology to scientific urban design and management (Pickett and Cadenasso, 2008). For urban flood management projects attempting to evaluate the effects of landscape and drainage design, $a$ priori understanding of the complex relationship between the runoff outcomes and the underlying imperviousness could help guide the experimental design and formulate hypotheses. For example, it is better to treat the TIA as the indicator rather than EIA for urban flood estimation in micro scaled urban catchments. Using EIA as the predictor in such urban catchments may result in underestimation of flood discharge volume and thus may fail to achieve the drainage design requirement. Additionally, reducing EIA benefits peak runoff mitigation and significantly postpones the runoff peak time for peak shifting and averting, which can alleviate the stormwater drainage requirements during drainage peak hours. Placing grass belts as filters or permeable paving materials on the asphalt roads and brick alleyways functioning mainly as EIA are good options (Hood et al., 2007; Gilroy and McCuen, 2009). Moreover, the current study shows that the runoff depth varied significantly among the subareas with different imperviousness compositions (Table III). These various in tributary runoff of the drainage units created the unique output of the entire residential catchment. Dietz and Clausen (2008) reported that modifications in a small catchment will result in more prominent runoff changes than if similar changes were made in a large watershed. Landscape alterations within these subareas thus will lead to different runoff responses and will exert different levels of drainage pressure to the entire drainage system. Therefore, reasonable balance of the spatial configuration of TIA and EIA may satisfy different flood control and drainage design requirements in urban regions. Prior optimized landscape design and stormwater inlet position enable the target catchment to be divided into several subareas with reasonable impervious fractions to reallocate flood risks.

\section{Limitations and uncertainties}

This study has limitations and uncertainties. The research was conducted with a high-intensity rainfall event for urban flooding consideration. As previously discussed, abundant stormwater may compromise the relative permeability of pervious landscapes and can promote runoff generation as infiltration excess (Figure 4), which usually leads to the underestimation of imperviousness performance. Under different rainfall conditions, significant variations in the relationship between runoff and underlying surfaces were found (Mejía and Moglen, 2010; Qin et al., 2013). Analysis of rainfall variances combined with imperviousness performance will thus be included in future studies. Additionally, EIA showed a relative lower $R^{2}$ in predicting LT, at $<0.5$. In fact, many other variables such as micro topography of the watershed, flow route, and climate descriptors have been determined as responsible factors affecting rainfall-runoff responses (Berne et al., 2004; Zhang et al., 2007). These potential factors may cause uncertainties in our results. Moreover, a classical storm sewer system with no source control devices was adopted in the WCY, where the rainfallrunoff processes differ from that of catchments with on-site stormwater management treatments (Hood et al., 2007). These factors may limit the validity of the results for the urban catchments with other types of stormwater management strategies. To obtain more general conclusions, further research with in situ and laboratory observations needs consider these limitations and uncertainties. 


\section{CONCLUSION}

This study investigated the hydrologic performances of two different impervious metrics, TIA and EIA, within a micro urban catchment. Sixty-nine drainage subareas $(<1$ ha) were delineated as basic study units, and the land cover and impervious information within each subarea were identified on the basis of GIS and remote sensing method. The runoff responses, total runoff, peak runoff, and lag time, were simulated by using a validated SWMM model. The roles of imperviousness on hydrologic responses within each subarea were investigated under a typical flood-induced rainfall condition and three different infiltration scenarios. The following conclusions can be summarized as that, under the rainfall and spatial conditions in this study:

1 TIA has a tangible contribution on both total and peak runoff depth than that by EIA.

2 EIA performs as an effective indicator in altering LT, whereas TIA lose significance. However, overall performance of EIA in predicting LT was relatively low $\left(R^{2}<0.5\right)$.

3 Different infiltration conditions result in different runoff responses of the selected subareas. However, the relative significances of TIA and EIA maintained stability with different infiltration conditions, indicating good applicability of the results.

\section{ACKNOWLEDGEMENTS}

We thank Ying XU, Wen LIU, and Ji ZHOU for their arduous and generous assistances and suggestions. The manuscript has been improved by the insightful comments and suggestions of the anonymous reviewers and the editor. This study was supported by the Key Project of the National Natural Science Foundation of China (41230633) and the Innovation Project of the State Key Laboratory of Urban and Regional Ecology of China (SKLURE2013-1-02).

\section{REFERENCES}

Alley WM, Veenhuis JE. 1983. Effective impervious area in urban runoff modeling. Journal of Hydraulic Engineering 109: 313-319.

Arnold CL, Gibbons CJ. 1996. Impervious surface coverage: the emergence of a key environmental indicator. Journal of the American Planning Association 62: 243-258.

Berne A, Delrieu G, Creutin JD, Obled C. 2004. Temporal and spatial resolution of rainfall measurements required for urban hydrology. Journal of Hydrology 299: 166-179.

Berthier E, Andrieu H, Creutin JD. 2004. The role of soil in the generation of urban runoff: development and evaluation of a 2D model. Journal of Hydrology 299: 252-266.

Boyd MJ, Bufill MC, Knee RM. 1993. Pervious and impervious runoff in urban catchments. Hydrological Sciences Journal 38: 463-478.
Boyd MJ, Bufill MC, Knee RM. 1994. Predicting pervious and impervious storm runoff from urban drainage basin. Hydrological Sciences Journal 39: 321-332.

Dietz ME, Clausen JC. 2008. Stormwater runoff and export changes with development in a traditional and low impact subdivision. Journal of Environmental Management 87: 560-566.

Dunne T, Leopold LB. 1978. Water in Environmental Planning. WH Freeman: New York, USA.

Finkenbine JK, Atwater JW, Mavinic DS. 2000. Stream health after urbanization. Journal of the American Water Resources Association 36: $1149-1160$

GB50014-2006. 2013. Code for design of outdoor wastewater engineering. (in Chinese)

Gilroy KL, McCuen RH. 2009. Spatio-temporal effects of low impact development practices. Journal of Hydrology 367: 228-236.

Guo YP, Adams BJ. 1998. Hydrologic analysis of urban catchments with event-based probabilistic models: 1. Runoff volume. Water Resources Research 34: 3421-3431.

Han WS, Burian SJ. 2009. Determine effective impervious area for urban hydrologic modeling. Journal of Hydrologic Engineering 14: 111-120.

Hatt BE, Fletcher TD, Walsh CJ, Taylor SL. 2004. The influence of urban density and drainage infrastructure on the concentrations and loads of pollutants in small streams. Environmental Management 34: 112-124.

Hood MJ, Clausen JC, Warner GS. 2007. Comparison of stormwater lag times for low impact and traditional residential development. Journal of the American Water Resources Association 43: 1036-1046.

Jacobson CR. 2011. Identification and quantification of the hydrological impacts of imperviousness in urban catchments: a review. Journal of Environmental Management 92: 1438-1448.

James W. 2003. Rules for Responsible Modeling. CHI: Guelph, Ontario, Canada.

Jha AK, Bloch R, Lamond J. 2012. Cities and Flooding: A Guide to Integrated Urban Flood Risk Management for the 21st Century. World Bank Publications: Washington, D.C., USA.

Jia Y, Ni G, Kawahara Y, Suetsugi T. 2001. Development of WEP model and its application to an urban watershed. Hydrological Processes 15: 2175-2194.

Jones JA, Swanson FJ, Wemple BC, Snyder KU. 2000. Effects of roads on hydrology, geomorphology, and disturbance patches in stream networks. Conservation Biology 14: 76-85.

Krebs G, Kokkonen T, Valtanen M, Setälä H, Koivusalo H. 2014. Spatial resolution considerations for urban hydrological modelling. Journal of Hydrology 512: 482-497.

Lee JG, Heaney JP. 2003. Estimation of urban imperviousness and its impacts on storm water systems. Journal of Water Resources Planning and Management 129: 419-426.

Leopold LB. 1968. Hydrology for Urban Land Planning: A Guidebook on the Hydrologic Effects of Urban Land use. United States Department of the Interior: Washington, D.C., USA.

Meierdiercks KL, Smith JA, Baeck ML, Miller AJ. 2010. Analyses of urban drainage network structure and its impact on hydrologic response. Journal of the American Water Resources Association 46: 932-943.

Mejía AI, Moglen GE. 2009. Spatial patterns of urban development from optimization of flood peaks and imperviousness-based measures. Journal of Hydrologic Engineering 14: 416-424.

Mejía AI, Moglen GE. 2010. Spatial distribution of imperviousness and the space-time variability of rainfall, runoff generation, and routing. Water Resources Research 46: W07509. DOI:10.1029/2009WR008568.

Nash JE, Sutcliffe J. 1970. River flow forecasting through conceptual models part I-a discussion of principles. Journal of Hydrology 10: 282-290.

Niemczynowicz J. 1999. Urban hydrology and water management-present and future challenges. Urban Water 1: 1-14.

Ogden FL, Raj Pradhan N, Downer CW, Zahner JA. 2011. Relative importance of impervious area, drainage density, width function, and subsurface storm drainage on flood runoff from an urbanized catchment. Water Resources Research 47: W07509. DOI:10.1029/2011WR010550.

Olivera F, DeFee BB. 2007. Urbanization and its effect on runoff in the Whiteoak Bayou watershed, Texas. Journal of the American Water Resources Association 43: 170-182.

Paul MJ, Meyer JL. 2008. Streams in the urban landscape. Urban Ecology 32: 207-231. 
Pickett STA, Cadenasso ML. 2008. Linking ecological and built components of urban mosaics: an open cycle of ecological design. Journal of Ecology 96: 8-12.

Qin H, Li Z, Fu G. 2013. The effects of low impact development on urban flooding under different rainfall characteristics. Journal of Environmental Management 129: 577-585.

Ragab R, Rosier P, Dixon A, Bromley J, Cooper JD. 2003. Experimental study of water fluxes in a residential area: 2 . Road infiltration, runoff and evaporation. Hydrological Processes 17: 2423-2437.

Ramier D, Berthier E, Andrieu H. 2011. The hydrological behaviour of urban streets: long-term observations and modelling of runoff losses and rainfall-runoff transformation. Hydrological Processes 25: 2161-2178.

Rodriguez F, Andrieu H, Morena F. 2008. A distributed hydrological model for urbanized areas-model development and application to case studies. Journal of Hydrology 351: 268-287.

Rossman LA. 2010. Storm water management model user's manual, version 5.0. Water Supply and Water Resources Division, National Risk Management Research Laboratory, Office of Research and Development, US Environmental Protection Agency.

Roy AH, Shuster WD. 2009. Assessing impervious surface connectivity and applications for watershed management. Journal of the American Water Resources Association 45: 198-209.

Shen ZY, Hou XS, Li W, Aini G. 2014. Relating landscape characteristics to non-point pollution in a typical urbanized watershed in the municipality of Beijing. Landscape and Urban Planning 123: 96-107.

Schmitt TG, Thomas M, Ettrich N. 2004. Analysis and modeling of flooding in urban drainage systems. Journal of Hydrology 299: 300-311.

Shuster WD, Bonta J, Thurston H, Warnemuende E, Smith DR. 2005. Impacts of impervious surface on watershed hydrology: a review. Urban Water Journal 2: 263-275.

Singh VP. 1997. Effect of spatial and temporal variability in rainfall and watershed characteristics on stream flow hydrograph. Hydrological Processes 12: 1649-1669.

Skotnickia M, Sowińskia M. 2013. The influence of depression storage on runoff from impervious surface of urban catchment. Urban Water Journal 12: 207-218.
Ssegane H, Tollner EW, Mohamoud YM, Rasmussen TC, Dowd JF. 2012. Advances in variable selection methods I: causal selection methods versus stepwise regression and principal component analysis on data of known and unknown functional relationships. Journal of Hydrology 438: $16-25$.

Talei A, Chua LH. 2012. Influence of lag time on event-based rainfallrunoff modeling using the data driven approach. Journal of Hydrology 438: 223-233.

Tayfur G, Singh VP. 2006. ANN and fuzzy logic models for simulating event-based rainfall-runoff. Journal of Hydraulic Engineering 132: $1321-1330$.

Walsh CJ, Fletcher TD, Ladson AR. 2005. Stream restoration in urban catchments through redesigning stormwater systems: looking to the catchment to save the stream. Journal of the North American Benthological Society 24: 690-705.

Wang Q, Zhang XX, Wei MJ, Zhou YW, Li P, Bai GY. 2011. Research summary of planning and design standards for storm water system in Beijing City. Water \& Wastewater Engineering 37: 34-39 in Chinese.

Watt WE, Chow KCA. 1985. A general expression for basin lag time. Canadian Journal of Civil Engineering 12: 294-300.

Wenger SJ, Peterson JT, Freeman MC, Freeman BJ, Homans DD. 2008. Stream fish occurrence in response to impervious cover, historic land use, and hydrogeomorphic factors. Canadian Journal of Fisheries and Aquatic Sciences 65: 1250-1264.

Yang GX, Bowling LC, Cherkauer KA, Pijanowski BC. 2011. The impact of urban development on hydrologic regime from catchment to basin scales. Landscape and Urban Planning 103: 237-247.

Zhang S, Liu C, Yao Z, Guo L. 2007. Experimental study on lag time for a small watershed. Hydrological Processes 21: 1045-1054.

Zhang X, Zhang X, Hu S, Liu T, Li G. 2012. Runoff and sediment modeling in a peri-urban artificial landscape: case study of Olympic Forest Park in Beijing. Journal of Hydrology 485: 126-138.

Zhang Y, Shuster W. 2014. Impacts of spatial distribution of impervious areas on runoff response of hillslope catchments: simulation study. Journal of Hydrologic Engineering 19: 1089-1100.

Zoppou C. 2001. Review of urban storm water models. Environmental Modelling \& Software 16: 195-231. 